\title{
A critical examination of the response competition hypothesis
}

\author{
DAVID J. STANG \\ Queens College of the City University of New York, Flushing, New York 11367
}

\begin{abstract}
Harrison and Matlin have proposed that novel stimuli elicit response competition (rc) which produces a tension state, but that exposure to these novel stimuli establishes response hierarchies, reducing $\mathrm{rc}$ and tension, and making the familiar less unpleasant than the novel. Several problems with the rc hypothesis are presented: (1) it does not adequately account for decreasing or inverted U-shaped relationships between frequency and affect; (2) the nature of $\mathrm{rc}$ is unclear and counterintuitive; (3) the operational definitions of rc and meaningfulness lack discriminant validity; (4) data supporting the rc hypothesis have alternate explanations. However, the considerable heuristic value of the hypothesis in generating research and other hypotheses is acknowledged.
\end{abstract}

The recent rediscovery of a relationship between how often one is exposed to a stimulus and how pleasant that stimulus seems has sparked curiosity as to the psychological processes involved. Why should familiarity sometimes breed contempt, and sometimes breed comfort, as has recently been shown?

One explanation of the phenomenon is in terms of "response competition," an idea that Harrison (1967, 1968) borrowed from Berlyne (1960 and earlier). The essence of this hypothesis is that novel stimuli are, in some respects, similar to various familiar stimuli and, consequently, elicit competing, incompatible, and therefore tension-producing responses. Any subsequent exposure to the stimulus permits establishment of a response hierarchy and reduction of the tension state. As this unpleasant tension state is reduced with repeated exposure, evaluative ratings of the stimuli are hypothesized to become less negative.

Since Harrison's elaboration of the response competition hypothesis, several problems have become evident. One problem is that, while the hypothesis is able to account for a positive relationship between exposure frequency and evaluative ratings, it does not, in its original formulation, account for the frequently obtained inverted U-shaped function (e.g., Smith \& Dorfman, 1975; Stang \& O'Connell, 1974) unless one accepts Saegert and Jellison's (1970) suggestion that "some optimal level of cognitive conflict is preferable to complete' reduction of response competition" (p. 557). This extension of the hypothesis strengthens the post hoc use of the hypothesis, but weakens its predictive usefulness. Further, neither form of the hypothesis can account for the fact that, with prolonged

I would like to thank Daniel Berlyne, Charles Cofer, Lynette Glasman, Albert Harrison, Ronald Ley, and Margaret Matlin, who provided helpful comments on a previous draft. Send reprint requests to David J. Stang, American Psychological Association, 1200 17th Street N.W., Washington, D.C. 20036. exposure, immediate evaluative ratings seem reliably to be a decreasing function of exposure frequency (e.g., Berlyne, 1970; Stang, 1975b; Stang, Campus, \& Wallach, 1975 ) or that the shape of the function seems to change with a rating delay (e.g., Harrison \& Crandall, 1972; Stang, 1974, 1975a).

Another problem with response competition concerns the unspecified nature of the competition between responses. Is emission difficulty what is meant? Probably not, for even with words for which we have many associations and poorly developed response hierarchies, subjects rarely find themselves "tongue tied" with associations competing for emission. For example, "kitchen" will elicit many associations, yet somewhat different sets of associations across trials on the same subject, but has short associative latencies. Perhaps the competition between responses refers to interassociation incompatibility. This interpretation also poses problems, for frequently used words tend to have more denotative meanings (see Matlin \& Stang, Note 1), suggesting that repeated exposure might increase rather than decrease response competition.

Perhaps the greatest difficulty with the response competition hypothesis is that the typical operational definition of response competition (latency to first free associate in a discrete free association task) is suspiciously similar to the typical operational definition of meaningfulness (number of free associations per unit time in a continuous free association task). Since meaningfulness seems to interact with exposure frequency in essentially the same way as response competition (cf. Amster \& Glasman, 1966; Hamid, 1972), we need to question the "discriminant validity" (Campbell \& Fiske, 1959) of the two concepts. Bousfield (1944) has shown that the rate of free association is dependent on the number of associations available: The greater the number of associations remaining, the shorter the associative latency. While the relationship is curvilinear, it does suggest that latency to 
first free association may be an indirect measure of meaningfulness (or vice versa). Several studies have directly examined the relationship between meaningfulness and associative latency. Beck, Phillips, and Bloodsworth (1962) report correlations of -.23 and -.19 between two measures of meaningfulness and associative latency. Ley and Karker (Note 3) report a correlation between judged meaningfulness and associative latency of -.77; Ley and Locascio (1970) report a correlation between meaningfulness and associative latency of -.80 . The evidence suggests that measures of response competition and meaningfulness may lack discriminant validity.

What of the other experimental evidence previously adduced in support of the response competition hypothesis? The finding that stimuli with short associative latencies are more pleasant (Harrison, 1968) than stimuli with longer latencies may be because associations tend to be pleasant (Matlin and Stang, Note 1) and stimuli with short associative latencies tend to have more associations; the more pleasant the associations, the more pleasant the stimulus. The finding that repeatedly exposed or frequently occurring stimuli have shorter associative latencies (e.g., Harrison \& Zajonc, 1970; Matlin, 1970) may be the result of forming more associations with repeated exposure and the strengthening of all initial associations during this exposure. The finding that frequently occurring or frequently exposed words elicit first associations which are easier to recall than first associations elicited by infrequent words (Matlin, 1970) may be a consequence of the greater communality of these associations (Hall \& Ugelow, 1957; Matlin, 1970), resulting from fuller understanding of their denotative meaning.

One other source of experimental support for the response competition hypothesis requires more extended discussion. Matlin (1970) paired nonsense stimulus words with evaluatively neutral familiar real words, and exposed them to subjects in such a way that some stimuli were always paired with the same associates, while others were paired with changing associates. Matlin found that the fewer the associations the experimenter supplied, the more positive the evaluative ratings of the stimulus. Harrison, Tutone, and McFadgen (1971) provide two variations on this paradigm, with similar results. It is possible that the more neutral associations the experiment supplied, the greater was the interference with the subjects' learning of the stimulus, and with the subjects' natural formation of associations to it. Recently, Kreindler and Hakmiller (Note 2) have found evidence that interference which inhibits learning also reduces liking of the stimulus. Similar interference may occur when subjects are instructed to vary their pronunciation of stimulus terms (Matlin, 1970, 1971).

This review suggests considerable problems with the response competition hypothesis. Whether these problems are resolved by response competition theorists is an open question. But whatever weaknesses the hypothesis now appears to have, the great heurisitic value of the hypothesis should not be minimized. It helped spark such interest in mere exposure phenomena that, within 5 years of its publication, there were five competing theories (Stang, 1973). It seems that exposure to the theory has produced a very healthy theoretical response competition.

\section{REFERENCE NOTE}

1. Matlin, M. W., \& Stang, D. J. The Pollyanna principle. Unpublished manuscript, State University of New York, College at Geneseo, and Queens College, 1976.

2. Kreindler, M., \& Hakmiller, K. Mere interference and attitudes. Unpublished manuscript. University of Connecticut, 1976.

3. Ley, R., \& Karker, J. Meaningfulness, associative reaction time, recognition latency, and pronunciability in free recall. Paper presented at the annual meeting of the American Psychological Association, Montreal, Canada, August 1973.

\section{REFERENCES}

Amster, A., \& Glasman, L. D. Verbal repetition and connotative change. Journal of Experimental Psychology, 1966, 71, 389-395.

Beck, R. C., Phillips, W. R., \& Bloodsworth, W. D. Associative reaction time as a function of association value of nonsense syllable stimuli. Psychological Reports, 1962, 10, 517-518.

Berlyne, D. E. Conflict, arousal, and curiosity. New York: McGraw-Hill, 1960.

BERLyNe, D. E. Novelty, complexity, and hedonic value. Perception \& Psychophysics, 1970, 8, 279-286.

Bousfield, W. A. An empirical study of the production of affectively tones items. Journal of General Psychology, 1944, 30, 205-215.

Campbell, D. T., \& Fiske, D. W. Convergent and discriminant validation by the multitrait-multimethod matrix. Psychological Bulletin, 1959, 56, 81-105.

Hall, J. F., \& Ugelow, A. Free association time as a function of word frequency. Canadian Journal of Psychology, 1957, 11, 29-32.

Hamid, P. N. Exposure frequency and affect. Unpublished doctoral dissertation, University of Waikato, Hamilton, New Zealand, 1972.

HARRISON, A. A. Response competition and attitude change as a function of repeated stimulus exposure (Doctoral dissertation, University of Michigan, 1967). Ann Arbor: University Microfilms No. 67-17, 774.

HARRISON. A. A. Response competition, frequency, exploratory behavior, and liking. Journal of Personality and Social Psychology, 1968, 9, 363-368.

Harrison, A. A., \& Crandall, R. Heterogeneity-homogeneity of exposure sequence and the attitudinal effects of exposure. Journal of Personality and Social Psychology, 1972, 21, 234-238.

Harrison, A. A., Tutone, R. M., \& McFadgen, D. G. Effects of frequency of exposure of changing and unchanging stimulus pairs on affective ratings. Journal of Personality and Social Psychology, 1971, 20, 102-111.

Harrison, A. A., \& Zajonc, R. B. The effects of frequency and curation of exposure on response competition and affective ratings. Journal of Psychology, 1970, 75, 163-169. 
LEY, R., \& DEAN, J. Effects of associative reaction time and meaningfulness in free recall of mixed and unmixed lists. Journal of Experimental Psychology, 1973, 98, 220-222.

LEY, R., \& Locascio, D. Associative reaction time and meaningfulness of CVCVC response terms in pairedassociate learning. Joumal of Experimental Psychology, $1970,83,445-450$.

Matrin, M. W. Response competition as a mediating factor in the frequency-affect relationship. Journal of Personality and Social Psychology, 1970, 16, 536-552.

Matisn, M. W. Response competition, recognition, and affect. Journal of Personality and Social Psychology, 1971, 19, 295-300.

SAEgert, S. C., \& Jellison, J. M. Effects of initial level of response competition and frequency of exposure on liking and exploratory behavior. Journal of Personality and Social Psychology, 1970, 16, 553-558.

Smith, G. F., \& Dorfman, D. D. The effect of stimulus uncertainty on the relationship between frequency of exposure and liking. Journal of Personality and Social Psychology, $1975,31,150-155$.
Stang, D. J. Six theories of repeated exposure and affect. JSAS Catalog of Selected Documents in Psychology, 1973, $3,126$.

Stang, D. J. Methodological factors in mere exposure research. Psychological Bulletin, 1974, 81, 1014-1025.

StANG, D. J. Effects of "mere exposure" on learning and affect. Journal of Personality and Social Psychology, 1975, 31, 7-12 (a).

STANG, D. J. When familiarity breeds contempt, absence makes the heart grow fonder: Effects of exposure and delay on taste pleasantness ratings. Bulletin of the Psychonomic Society, 1975, 6, 273-275 (b).

Stang, D. J., Campus, N., \& Wallach, C. Exposure duration as a confounding methodological factor in projective testing. Journal of Personality Assessment, 1975, 39, 583-586.

Stang, D. J., \& O'Connell, E. J., JR. The computer as experimenter in social psychological research. Behavior Research Methods \& Instrumentation, 1974, 6, 223-232.

(Received for publication March 4, 1976.) 